Youth Resiliency:

\title{
Assessing Students' Capacity for Success at School
}

\section{Tyrone Donnon, Wayne Hammond and Grant Charles}

A $s$ opposed to the problem-based approach of dealing with specific at-risk behaviours in secondary schools, the purpose of Resiliency Canada's self-reported Youth Resiliency: Assessing Developmental Strengths (YR:ADS) questionnaire is to provide a statistically sound and research-based approach to understanding the factors or strengths that are related to the development of adolescent resiliency. Working in collaboration with the Calgary Board of Education from a strength-based approach to understanding child and adolescent development, Resiliency Canada introduces the youth resiliency framework and presents the findings from a large urban sample of grade 7 to 9 students $(\mathrm{N}=2291)$. A framework for understanding the construct of resiliency that results from the investigation of intrinsic and extrinsic factors that influence the development of youth resiliency and adaptive behaviour is presented. Outcomes of this research supports both the protective-protective and challenge models of resiliency.

\section{Overview}

The study of protective factors, or the more recent attempts at conceptualizing the phenomena of individual resiliency, has been prevalent in the social science and health-related research communities for decades. Although there has been considerable research in- terest in the concept of resilience, ambiguities regarding terminology, definitions, and the variability related to contributing factors and corresponding risk experiences continue to question the utility of the resiliency phenomena as a valid scientific construct (Luthar, Cicchetti \& Becker, 2000; Masten et. al., 1999; Resnick, 2000). Nevertheless, a long history of research into the factors that contribute to an understanding of the maladaptive behaviours of atypical youth generated considerable interested in identifying the forces that would lead to healthy adaptive lifestyles (Gramezy, 1991; Radke-Yarrow \& Sherman, 1990; Rae-Grant et. al., 1989; Rutter, 1990). Initiated by Emmy Werner's longitudinal studies in Hawaii of low socio-economic children (Werner \& Smith, 1982; Werner, 1989), a systemic search for the prevalent elements of resiliency adaptation has expanded to include research into a multitude of individual characteristics and contextual settings. In particular, personal or intrinsic characteristics of resilient children have been studied to determine the importance of such qualities as self-esteem (Dumont \& Provost, 1999; Masten \& Gramezy, 1985; Rutter, 1987), self-efficacy (Masten \& Coatsworth, 1998), and intellectual functioning (Freitas \& Downey, 1998; Masten et. al., 1999). Nevertheless, there was equal acknowledgement from researchers that a variety of contextually related extrinsic variables were associated with stress resilient children and their immediate environment. As such, a major focus has been place on youth in low socioeconomic conditions (Gramezy, 1991; Werner \& Smith, 1982), dysfunctional family settings (Beardlee \& Podorefsky, 1988; Ferguson \& Lynsky, 1996; Grossman et. al., 1992; Rutter, 1987), and multifaceted constructs such as competency (Masten, Best \& Garmezy, 1990) and coping skills (Dumont \& Provost, 1999).

Three main areas of focus in identifing variables of influence;

a) personal attributes,

b) family characteristics, and

c) other external support systems such as peers, school and the community are reported (Gramezy 1985; Masten \& Gramezy, 1985; Luthar, Cicchetti \& Becker, 2000; Werner \& Smith, 1982).

Figure 1, outlines support for two broad sets of factors that are related to a general framework for understanding the development of resiliency. These include 1) intrinsic strengths - personality characteristics or attributes of the individual (e.g., empathy, self-esteem, self-efficacy), and 2) extrinsic strengths - interpersonal settings or environments (e.g., supportive family, positive peer influence, caring school and community environments).

As researchers strive to identify potential solutions to specific problem-based diagnoses, less effort has been placed on the cumulative effects that protective or resiliency factors may play in allowing youth to lead healthy and productive lifestyles (Scales \& Leffert, 1999). As such there is concern that young people are not being provided with appropriate social support systems that promote personal development and adequate caring and supportive 


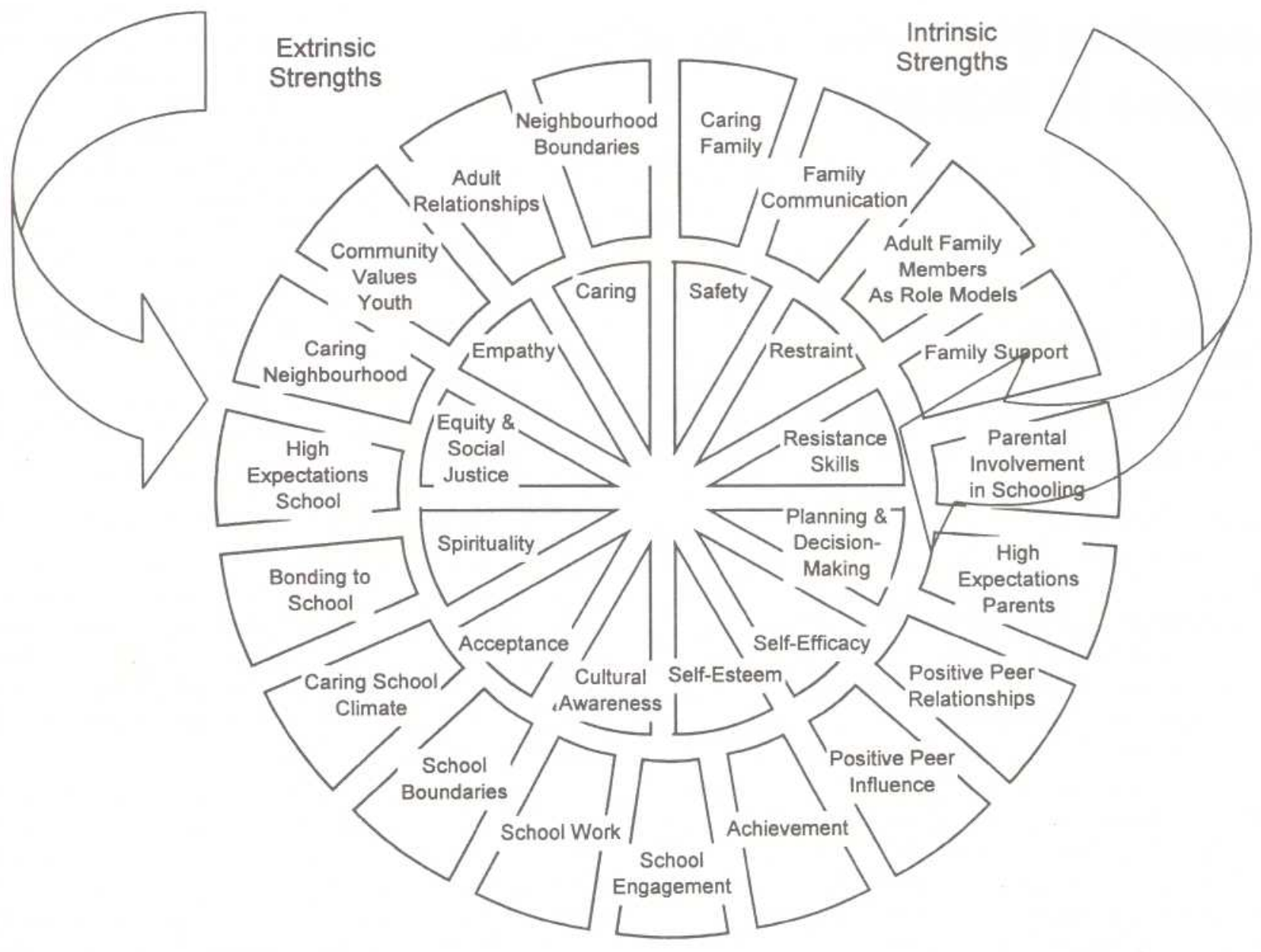

Figure 1. The YR:ADS questionnaire resiliency framework and 31 developmental strengths model.

relationships with families, peers, schools and communities (Atkinson, 1987; Jessor, et. al., 1995; Kupersmidt \& Coie, 1990; Wolkow \& Ferguson, 2001). Particularly in large urban areas, it has become difficult to establish adequate guidance or positive opportunities for youth to receive constant and consistent nurturing of the values, beliefs and competencies they need to become independent, contributing members of society particularly during school years and beyond (Brooks-Gunn, et. al., 1993; Jessor, 1993; Scales \& Leffert, 1999; Yates \& Youniss, 1996).
During the past decade, research has shown that policies and programs for youth that focus on preventing specific youth behaviour problems (e.g., vandalism, drug abuse) generally are unable to report any long-term benefits (Benson, et. al., 1998; Brown \& Horowitz, 1993; Hawkins, Catalano \& Miller, 1992; Herman-Stahl \& Petersen, 1996; Scales, 1990; Windle, 1992). With the expectations of heightened resilience strengths in youth, various efforts have shifted towards the development of a resiliency framework and model that would have implications for determining social and psychological well-being in children and adolescents (Cowen \& Work, 1988). Concurrently, practitioners in the fields of social work, education and psychology have adopted the concept of youth resiliency as it pertains to identifying potential services and prevention programs in community (Bartle, et. al., 2002; Cameron \& Cadell, 1999; Grizenko \& Fisher, 1992; Wolkow \& Ferguson, 2001). From an applied research perspective, the focus on a comprehensive framework for understanding the development 
of youth resiliency has enabled school districts and community stakeholders to focus on a strength-based approach to addressing child and youth developmental issues (Blyth \& Leffert, 1995; Scales \& Leffert, 1999).

\section{Models of Resiliency}

Not until recently has the concept of resiliency been presented as a viable scientific construct (Brook et. al., 1990; Garmezy, Masten \& Tellegen, 1984; Masten et. al, 1988; Moran \& Eckenrode, 1992; Rutter, 1985; Wolin \& Wolin, 1995). The ability to overcome and thrive despite exposure to stress-related or adversarial situations is a reflection of the individual's resiliency profile. As such, there are currently four models of resiliency proposed (HolligterWagner, Foshee \& Jackson, 2001): 1) the compensatory model states that each risk and protective factor combine cumulatively to have an independent and direct influence on the predicted outcomes; 2) the risk-protective model emphasizes the presence or absence of the protective factor in predicting the relationship that will exist between risk and outcome; 3 ) the protective-protective model expands on the interactive risk-protective model by positing that the risk and outcome relationship decreases with each protective factor present; and 4) the challenge model purports a curvilinear relationship between the risk factor and predicted outcome. In this model, low levels of risk act as learning experiences that encourage the development of coping strategies and actually may weaken problem behaviour outcomes initially (Hawkins, Catalano \& Miller, 1992; Rutter, 1985, 1987). With increased risk levels, however, the problem behaviour escalates in an almost exponential or curvilinear relationship indicating the diminishing returns that come from having very few or no protective factors in an individual's resiliency profile.

\section{Assessing Developmental Strengths and the Youth Resil- iency Profile}

The YR: ADS questionnaire is designed to allow for the flexibility of use in various applied and scientific based research studies. In particular, the instrument consists of three separate sections: 1) 94 items are used to measure the 10 factors or 31 development strengths subscales associated with the resiliency framework (see Figure 1), 2) several items are used to measure frequencies that are considered to reflect potentially negative- (e.g., substance abuse, antisocial behaviour,...) and positive-related behaviours (e.g., success in school, values diversity, maintains good health, exhibits leadership,...), and 3) various demographic questions are included to identify various independent or extraneous variables (e.g., school/community, gender, age, grade, family setting, language, mother's/father's level of education). The ability to manipulate the demographic and behavioural indicators has been attractive to other researchers interested in studying the relationships between the resiliency framework and the specificity of other conditions (e.g., gambling, youth gangs) or concepts (e.g., attachment, self-concept). Using a dichotomous split to generate an individual resiliency profile summary, a sum total number of strengths out of a possible 31 were tabulated for each youth.

\section{Findings}

The summary of findings presented here represent data derived from the first large-scale administration of the YR: ADS questionnaire conducted in 5 junior high schools in the Calgary
Board of Education. The 2291 completed questionnaires came from culturally diverse junior high schools with populations that range between 347 to 567 students. There was a fairly even distribution between males ( $\mathrm{N}=1121$, $48.9 \%$ ) and females ( $N=1170$, $51.1 \%$ ), and by grade levels; grade $7(\mathrm{~N}=712,31.1 \%)$, grade $8(\mathrm{~N}=790$, $34.5 \%)$ and grade $9 \quad(\mathrm{~N}=789$, $34.4 \%)$.

In general, the majority of youth indicated that they had a relatively large number of the resiliency factors, with the average youth 'having' 21 out of a possible 31 developmental strengths. In total, $81 \%$ reported having a "caring family", $67 \%$ had "positive peer relationships", $81 \%$ believe their school has "high expectations", and $88 \%$ have high "self-efficacy." Only $31 \%$ of the total, however, indicating they have a "caring neighbourhood" and $34 \%$ believing that the "community values youth." By grade this downward trend becomes even more apparent. The percentage of youth in grade 7 who indicate they have strengths like "adult relationships" or "community values youth" drops from $45 \%$ to $28 \%$ and $42 \%$ to $26 \%$ by grade 9 respectively.

For applied purposes in school-based settings, the developmental strengths have been presented in comprehensive reports to various community stakeholders (i.e., community members, school personnel, service sector representatives) as dichotomous variables. Of particular concern to community stakeholders are the low values obtained for all four community strengths measures. In generating a report that would best meet the communication needs of school and community members, data is presented in anonymous, aggregated percentages that reflect whether the youth "have" or 
"don't have" the particular strength. The use of the dichotomous reporting format in the main text by percentages has allowed for an easy interpretation of youth developmental strengths by sex, grade and total sample. Comparing the continuous distributions arrived at for items on each subscale, youth in this study were defined as having the strength if their combine score is less than 2.50 on a 1 (strongly agree) to 5 (strongly disagree) point scale. The benefit of this approach is that the face validity of an individual's response is not lost by the establishment of an arbitrary line, for example, at the mean or a standard deviation point from the sample data.

From the aggregated sample data presented in this article ( $\mathrm{N}=2291$ ),

$5 \%$ have $0-5$ strengths,

$6 \%$ have $6-10$

$11 \%$ have $11-15$

$18 \%$ have $16-20$

$28 \%$ have $21-26$

and $32 \%$ have $26-31$

The two extreme developmental strengths categories each have 6 possible options (e.g., 0, 1, 2, 3, 4, and 5) while the four middle categories have 5 (e.g., 6, 7, 8, 9, and 10).

The relationship between the six developmental strength categories to the percentage of youth by sex that engage frequently in two or more of twelve high risk behaviour patterns as measured by the YR:ADS questionnaire is shown in Figure 2. When this is compared with self-reported problem behaviour outcomes, the findings support the additive influence of developmental strengths as purported by the protective-protective model of resiliency. Although males $(32.2 \%, \mathrm{~N}$ $=1121$ ) appear to be more likely than females $(24.2 \%, \mathrm{~N}=1170)$ to engage in two or more high risk behaviour patterns, on average, both demonstrate the importance of having developmental strengths to restraint from at-risk behaviours.

A similar linear relationship is also found for total positive behaviours in that an increase in developmental strength category reflects a corresponding increase in the percentage of youth that engage in more constructive behaviour patterns. When the risk behaviour patterns are examined separately, there appears to be considerable variation between the two extreme developmental strength categories (i.e., percentage of youth in the $0-5$ DS and the $26-31$ DS categories) and the percentage of youth that engage in problem behaviours habitually.

Although it is not clear as to whether or not the enhancement of coping ability is reflected in low levels of risk, the findings for a number of risk behaviour indicators (e.g., alcohol consumption, used of tobacco, skipping school,...) support a curvilinear relationship between incident of risk exposure and problem behaviour as a function of the protective factors that exist in the aggregated youth resiliency profiles.

\section{Building Inter-Collaborative Ca-} pacity Through a

\section{Strength-Based Approach}

The additive effect of both intrinsic and extrinsic strengths have shown that youth with strong resiliency profiles are able to cope with adversity more effectively than those that experience few if any of the developmental strengths. This becomes apparent when developmental strength categories are compared with individual behaviour patterns to support both the additive effects

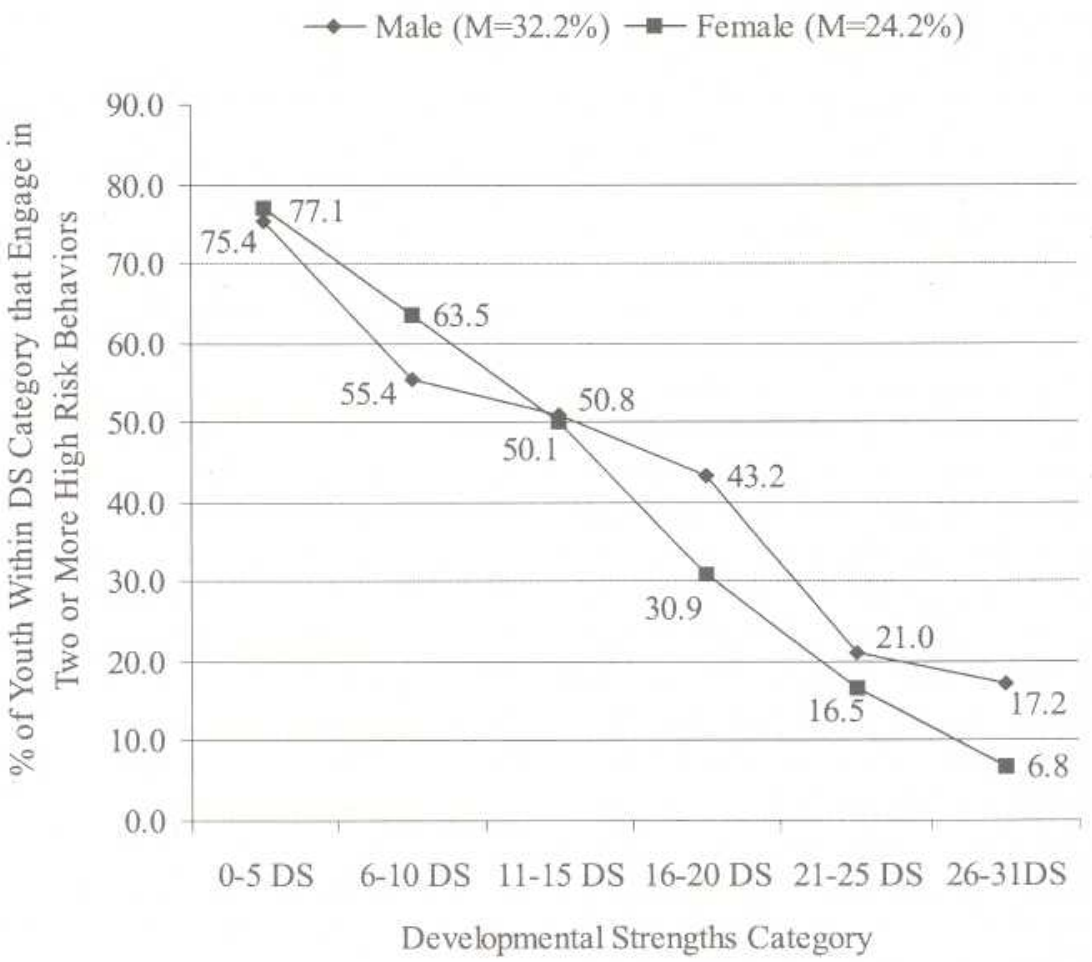

Figure 2. The effect of Sex $x$ Developmental Strengths on engagement in two or more high risk behaviours $(\mathrm{N}=2291)$. 
of a general protective-protective and behavior specific challenge models of resiliency. In particular, the findings consistently show that youth with strong resiliency profiles tend to participate in more positive or constructive activities and are less likely to engage in risk taking behaviours. In particular, there is clearly support for a comprehensive framework that looks at the role of strengths in promoting the development of youth resiliency. It also suggests a strength-based approach that can be used by educators, parents, students and members of the community to promote the development of resiliency through inter-collaborative strategies that address the needs of youth in their particular school. As such, the developmental strengths that contribute to resiliency exist within the individual and through the situational and relational experiences related to family, peers, school and community.

Resiliency Canada's primary goal is to provide an understanding through applied and scientific research of why some children and adolescents are more resilient than others in the face of adversity. Based on this research, and the literature on resiliency and adolescent development, the developmental strengths model identifies the resiliency factors that encourage and enhance the well-being and development of all youth in our communities. What is most attractive about the YR:ADS questionnaire to the school district and the community representatives that worked with the schools are that the results focused on a comprehensive, strength-based approach to understanding youth development. In particular, the extrinsically and intrinsically defined developmental strengths model provides a theoretical and holistic framework for under- standing the importance of youth resiliency.

Working from this strengthbased model of understanding youth development, we emphasize the positive aspects of individual differences in understanding what extrinsic and intrinsic strengths contribute to optimal child and adolescent development and school success.*

*This work was sponsored through the United Way of Calgary by the Calgary Children's Initiative, and involved the collaborative efforts of a number of other representatives from non-profit agencies (i.e., Aspen Family and Community Services, Boys and Girls Club, Communities in Action for Children and Youth, and the YMCA), municipal organizations (i.e., City of Calgary, Calgary Health Region), and the tremendous support of educators from the Calgary Board of Education.

\section{Selected References}

Atkinson, R. (1987). The development of purpose in adolescence: Insights from the narrative approach. Adolescent Psychiatry, 14, 149-161.

Bartle, E. E., Couchonnal, G., Canda, E. R., \& Staker, M. D. (2002). Empowerment as a dynamically developing concept for practice: Lessons learned from organizational ethnography. Social Work, $47(1), 32-43$.

Beardlee, W. R. \& Podorefsky, D. (1988). Resilient adolescents whose parents have serious affective and other psychiatric disorders: Importance of self-understanding and relationships. American Journal of Psychiatry, 145(1), 63-69.

Benson, P.L., Leffert, N., Scales, P.C.,\& Blyth, D.A. (1998). Beyond'the "village" rhetoric: Creating healthy communities for children and adolescents. Applied Developmental Science, 2, 138-159.

Blyth, D. A., \& Leffert, N. (1995). Communities as contexts for adolescent development: An empirical analysis. Journal of Adolescent Research, 100, 64-87.

Brook, J. S., Brook, D. W., Gordon, A. S., Whiteman, M., \& Cohen, P. (1990). The psychological etiology of drug use: A family interactional approach. Genetic, Social, and General Psychology Monographs, 116, 111-267.

Brooks-Gunn, J., Duncan, G. J., Klebanov, P., \& Sealand, P. (1993). Do neighborhoods influence child and adolescent development? American Journal of Sociology, 99. 353-395.

Brown, J. H., \& Horowitz, J. E. (1993). Deviants and deviance: Why adolescent substance use prevention programs do not work. Evaluation Review, 17, 529-555.

Cameron, G., \& Cadell, S. (1999). Fostering empowering participation in prevention programs for disadvantaged children and families: Lessons from ten demonstration sites. Canadian Journal of Community, 18(1), 105-121.

Cowen, E. L., \& Work, W. C. (1988). Resilient children, psychological wellness, and primary prevention. American Journal of Community Psychology, 16(4), 591-607.

Dumont, M., \& Provost, M. A. (1999). Resilience in adolescents: Protective role of social support, coping strategies, self-esteem, and social activities on experience of stress and depression. Journal of Youth and Adolescence, 28(3), 343-363.

Ferguson, D. M., \& Lynsky, M. T. (1996). Adolescent resiliency to family adversity. Journal of Child Psychology and Psychiatry and Allied Disciplines, 37 (3), 281-292.

Freitas, A. L., \& Downey, G. (1998). Resilience: A dynamic perspective. International Journal of Behavioral Development, 22(2), 263-285.

Garmezy, N . (1985). Stress-resistant children: The search for protective factors. In J. E. Stevenson (ed.), Recent research in developmental psychopathology: Journal of Child Psychology and Psychiatry Book Supplement \#4 (pp. 213-233). Oxford: Pergamon Press.

Garmezy, N. (1991). Resiliency and vulnerability to adverse developmental outcomes associated with poverty. American Behavioral Scientist, 34(4), 416-430.

Garmezy, N., Masten, A. S., \& Tellegen, A. (1984). The study of stress and competence in children: A building block for developmental psychopathology. Child Development, 55, 97-111.

Grizenko, N., \& Fisher, C. (1992). Review of studies of risk and protective factors for psychopathology in children. Canadian Journal of Psychiatry, 37(10), 711-721.

Grossman, F. K., Beinashowitz, J., Anderson, L., Sakurai, M., \& Flaherty, M. (1992). Risk and resilience in young adolescents. Journal of Youth and Adolescence, 21 (5), 529-550.

Hawkins, J. D., Catalano, R. F., \& Miller, J. Y. (1992). Risk and protective factors for alcohol and other drug problems in 
adolescence and early adulthood: Implications for substance abuse prevention. Psychological Bulletin, 172,64-105.

Herman-Stahl. M. \& Petersen, A. C. (1996). The protective role of coping and social resources for depressive symptoms among young adolescents. Journal of Youth and Adolescence 25 733-753.

Hollister-Wagner, G. H., Foshee, V. A., \& Jackson, C. (2001). Adolescent aggression: Models of resiliency. Journal of Applied Social Psychology, 31(3), 445-466.

Jessor, R. (1993). Successful adolescent development among youth in high-risk settings. American Psychologist, 48, 117-126.

Jessor, R., Van Den Bos, J., Vanderryn, J., Costa, F.M., \& Turbin, M. S. (1995). Protective factors in adolescent problem behavior: Moderator effects and developmental change. Developmental Psychology, 31, 923-933.

Kupersmidt, J. B., \& Coie, J. D. (1990). Preadolescent peer status, aggression, and school adjustment as predictors of externalizing problems in adolescence. Child Development, 61, 1350-1362.

Luthar, S. S., Cicchetti, D., \& Becker, B. (2000). The construct of resilience: A critical evaluation and guidelines for future work. Child Development, 71(3), 543-562.

Masten, A. S., Best, K. M., \& Garmezy, N. (1990). Resiliency and development: Contributions from the study of children who overcome adversity. Development and Psychopathology, 2, 425-444.

Masten, A. S., \& Coatsworth, J. D. (1998). The development of competence in favorable and unfavorable environments: Lessons from research on successful children. American Psychologist, 53, 205-220.

Masten, A. S., \& Garmezy, N. (1985). Risk, vulnerability, and protective factors in developmental psychology. In B. Lahey \& A. Kazdin (Eds.), Advances in Clinical Child Psychology, Vol. 8 (pp. 1-52). New York, NY: Plenum Press.

Masten, A. S., Garmezy, N., Tellegen, A., Pellegrini, D. S., Larkin, K., \& Larsen, A. (1988). Competence and stress in school children: The moderating effects of individual and family qualities. Journal of Child Psychology and Psychiatry, 29, 745-764.

Masten, A. S., Hubbard, J. J., Gest, S. D., Tellegen, A., Garmezy, N., \& Ramirez, M.L. (1999). Competence in the context of adversity: Pathways to resilience and maladaptation from childhood to late adolescence. Development and Psychopathology, 11, 143-169.

Moran, P. B., \& Eckenrode, J. (1992). Protective personality characteristics among adolescents from maltreating homes. Child Abuse and Neglect, 16, 743-754.

Radke-Yarrow, M., \& Sherman, T. (1990). Hard growing: children who survive. In J. Rolf, A. S. Masten, D. Cicchetti, K. H. Nuechterlein and S. Weintraub (Eds.), Risk and protective factors in the development of psychopathology (pp. 97-119). New York: Cambridge University Press,

Rae-Grant, N., Thomas, B. H., Offord, D. R. \& Boyle, M. H. (1989). Risk, protective factors, and the prevalence of behavioral and emotional disorders in children and adolescents. Journal of American Academy of Child and Adolescent Psychiatry, 28(2), 262-268.

Resnick, M. D. (2000). Protective factors, resiliency, and healthy youth development. Adolescent Medicine, 11 (1), 157-164.

Rutter, M. (1985). Resilience in the face of adversity: Protective factors and resistance to psychiatric disorder. British Journal of Psychiatry, 147, 598-611.

Rutter, M. (1987). Psychosocial resilience and protective mechanisms. American Journal of Orthopsychiatry, 57(3), 316-331.

Rutter, M. (1990). Psychosocial resilience and protective mechanisms. In J. Rolf, A. S. Masten, D. Cicchetti, K. H. Nuechterlein and S. Weintraub (Eds.), Risk and protective factors in the development of psychopathology (pp. 181-214). New York: Cambridge University Press.

Scales, P. C. (1990). Developing capable young people: An alternative strategy for prevention programs. Journal of Early Adolescence, 10, 420-438.

Scales, P. C., \& Leffert, N. (1999). Developmental assets: A synthesis of the scientific research an adolescent development. Minneapolis, MN: Search Institute.

Werner, E. E. (1989). High-risk children in a young adulthood: A longitudinal study from birth to 32 years. American Journal of Orthopsychiatry, 59 (1), 72-81.

Werner, E. E., \& Smith, R. S. (1982). Vulnerable, but invincible: A longitudinal study of resilient children and youth. New York: McGraw-Hill.

Windle, M. (1992). A longitudinal study of stress buffering for adolescent problem behaviors. Developmental Psychology, 28, 522-530.

Wolkow, K. E. \& Ferguson, H. B. (2001). Community factors in the develop- ment of resiliency: Considerations and future directions. Community Mental Health Journal, 37(6), 489-498.

Wolin, S., \& Wolin, S. (1995). Resilience among children growing up in substance abusing families. Pediatric Clinics of North America, 42, 415-429.

Yates, M., \& Youniss, J. (1996). A developmental perspective on community service in adolescence. Social Development, $5,85-111$.

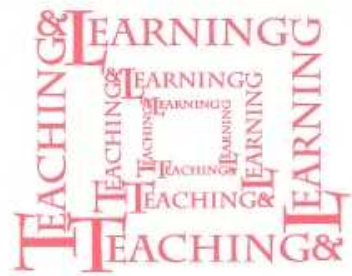

continued from $\mathrm{pg} .22$

\section{Assessing Children's Spelling}

Ruth McQuirter Scott

\section{References}

Beers, J. \& Henderson, E. (1977). A study of developing orthographic concepts among first grade children. Research in the Teaching of English, 11(2), 133-148.

Education Department of Western Australia (1995). First steps: Spelling resource book. Melbourne: Longman Australia.

Gentry, R. (1982). You can analyze developmental spelling. Teaching K-8, 15(9), 44-45.

Gentry, R. (1993). Teaching kids to spell. Portsmouth: Heinemann.

Henderson, E. (1981). Learning to read and spell. DeKalb: Northern Illinois University Press.

Henderson, E. (1990). Teaching spelling. Boston: Houghton Mifflin.

Phenix, J. \& Scott-Dunne, D. (1991). Spelling instruction that makes sense. Toronto: Pembroke.

Scott, R. (1993). Spelling: Sharing the secrets. Toronto: Gage.

Tarasoff, M. (1990). Spelling strategies you can teach. Victoria: Pixelart Graphics.

Tarasoff, M. (1992). A guide to children's spelling development for parents and teachers. Victoria: Active Learning Institute.

Templeton, S. (1983). Using the spelling/meaning connection to develop word knowledge in older students. Journal of Reading, 27(1), 8-15.

The Ontario Curriculum, Grades 1-8: Language (1997). 